\title{
Anti-inflammatory and ulcerogenic activities of thiazolidine-4-ones in rats
}

\author{
Shiva Murthy N. ${ }^{1 *}$, Srinivas.$^{2}$, Shanthi M. ${ }^{3}$
}

${ }^{1}$ Department of Pharmacology, DM Wayanad Institute of Medical Sciences, Wayanad, Kerala, India

${ }^{2}$ Department of Pharmacology, Koppal Institute of Medical Sciences, Koppal, Karnataka, India

${ }^{3}$ Department of Pathology, Vijayanagara Institute of Medical Sciences, Bellary, Karnataka, India

Received: 10 October 2018 Accepted: 01 November 2018

\section{*Correspondence to:}

Dr. Shiva Murthy N., Email: shivuindia@gmail.com

Copyright: (C) the author(s), publisher and licensee Medip Academy. This is an openaccess article distributed under the terms of the Creative Commons Attribution NonCommercial License, which permits unrestricted noncommercial use, distribution, and reproduction in any medium, provided the original work is properly cited.

\begin{abstract}
Background: NSAIDS are associated with side effects and research should continue for developing safer drugs. This study aims to evaluate newer thiazolidine-4-ones for their anti-inflammatory and ulcerogenic activities in wister rats.

Methods: Five groups of wister rats, 6 in each were used. Anti-inflammatory and ulcerogenic activities of diclofenac $(30 \mathrm{mg} / \mathrm{kg})$, nimesulide $(50 \mathrm{mg} / \mathrm{kg})$, thia-1 $(50 \mathrm{mg} / \mathrm{kg})$ and thia-2 $(50 \mathrm{mg} / \mathrm{kg})$ are compared with control group (4\% Gum Acacia). Carrageenin-induced paw edema, formaline induced acute peritonitis and cotton pellet-induced granulomatous tissue formation models were used for evaluating anti-inflammatory activity. After removing cotton pellets with granuloma on $8^{\text {th }}$ day gastric ulcerogenicity was assessed by using macroscopic and microscopic scoring of ulcers.

Results: Diclofenac, nimesulide and thia 2 reduced both paw edema and peritoneal exudate volume significantly $(\mathrm{p}<0.01)$. Wet weight of cotton pellets reduced significantly $(\mathrm{p}<0.01)$ by diclofenac, nimesulide and thia 2 . Diclofenac $(\mathrm{p}<0.01)$ and thia $2(\mathrm{p}<0.05)$ reduced dry weight of cotton pellets significantly. nimesulide and thia-1 reduced it by $19.14 \%$ and $2.68 \%$ respectively and was considered statistically not significant $(\mathrm{p}>0.05)$. Nimesulide, thia- 1 and thia- 2 did not increase gastric ulcer score significantly $(\mathrm{p}>0.05)$. Diclofenac increased ulcer score significantly $(\mathrm{p}<0.01)$.

Conclusions: Thia-2 demonstrated significant anti-inflammatory activity in acute and chronic models. In addition to inhibition of cyclooxygenase pathway, PPAR agonistic activity may be involved in its anti-inflammatory activity. No significant ulcerogenicity was observed on comparing with nimesulide and control. Further in-vitro and in-vivo studies are recommended to confirm the results of this study.
\end{abstract}

Keywords: Anti-inflammatory, Diclofenac, Nimesulide, NSAIDs, Thiazolidine4-ones, Ulcerogenicity

\section{INTRODUCTION}

Tissue damage initiates complex process called inflammation which involves movement of inflammatory cells such as macrophages, neutrophils and lymphocytes to the site of injury and release of specialized chemical substances like vasoactive amines and peptides, eicosanoids, pro-inflammatory cytokines and acute-phase proteins. Inflammation arrests further tissue damage and restores tissue functions after healing. ${ }^{1}$ Three phases of inflammation such as; first with increased vascular permeability with exudation of fluids into the interstitial space; second phase with infiltration of leukocytes into the tissue and third with granuloma formation and tissue repair. While evaluating the anti-inflammatory activities 
of newer substances, their ability to reduce all the three phases of inflammation is studied. ${ }^{2}$

Prolonged inflammation can result in organ damage and/or failure. Therefore, limiting this deleterious process and its course by using anti-inflammatory agents (like Nonsteroidal anti-inflammatory drugs (NSAIDs), steroids and immunesuppressants) is important. Anti-inflammatory agents are conventionally used in all forms of inflammatory conditions., ${ }^{1,2}$ NSAIDs with 70 million prescriptions in United States and 20 million in United Kingdom are believed to be the most widely prescribed drug group worldwide. Their anti-inflammatory and analgesic properties are increasingly used in this context. ${ }^{3}$ World's $10 \%$ of population is reported with gastric ulcer. It may be caused due to imbalance between protective factors (such as adequate blood flow, secretion of prostaglandins (PGs), mucin, nitric oxide, bicarbonate and growth factors) and aggressive agents (such as infection with $H$. pylori, stressful conditions, free radicals, inadequate dietary habits with alcohol consumption and NSAIDs, increased secretion of hydrochloric acid and pepsin). ${ }^{4} 34-46 \%$ of patients consuming NSAIDS are reported with gastrointestinal damage. This is attributed to inhibition of protective cyclooxygenase (COX-1) leading to reduced PGs synthesis in gastric mucosa. Other adverse events of NSAIDs are hypersensitivity, angioedema, hepatic failure, headache, haemolytic anaemia, hyperglycaemia, osteoporosis, immunodeficiency-related problems etc. On the other hand, beneficial effects of NSAIDs are linked to the inhibition of inducible cyclooxygenase (COX-2) enzyme. . $^{2,5,6}$

Thiazolidine derivatives (TZDs) are reported to alter various physiological processes such as inflammation, cell proliferation, angiogenesis and glucose metabolism with significant beneficial effects as anti-diabetic, antimicrobial, anti-chagasic, anti-HIV, anti-inflammatory, anti-atherosclerotic and anti-cancer agents. ${ }^{7-10}$ TZDs are reported to act through Peroxisome proliferator-activated receptors (PPARs). The three types of PPARs namely PPAR $\alpha$, PPAR $\delta$ and PPAR $\gamma$, are encoded by different genes. Increased inflammatory response by leukotriene B4 and arachidonic acid is reported in PPAR $\alpha$ deficient status in mice. Some TZDs like rosiglitazone, pioglitazone and troglitazone were clinically and commercially available as antidiabetic drugs. ${ }^{8}$ As discussed above, currently available NSAIDS are associated with unwanted side effects and have their own limitations. Hence there is a need for better anti-inflammatory drugs with fewer side effects. With this background, this study was initiated to evaluate anti-inflammatory and ulcerogenic activities of thiazolidine-4-ones in wister rats.

\section{METHODS}

\section{Drugs and instruments}

Diclofenac and nimesulide as standard NSAIDs (donated by Systopic Pharmaceuticals Pvt Ltd., New Delhi, India);
Two thiazolidine-4-ones synthetic compounds as test drugs: thia-1 [2-(4-chlorophenyl)-3- $\beta$-(N-benzene, sulphonyl, anilino) propionyl amido-1,3,-thiazolidine-4one] and thia-2 [2-(4-chlorophenyl)-3- $\beta$-(N-tolune, sulphonyl, p-tolidino) propionyl amido-1,3,-thiazolidine4-one] (provided by Dr SC. Bennur, Professor, Organic chemistry department, Karnataka University, Dharwad.); gum acacia (Liberty Pharmaceuticals, Bombay) as control and suspending agent; formalin (Ajay Chemicals, Palakkad) as phlogistic agent in ascites model and as preservative for the specimens; carrageenan (donated by pharmacology department, Bangalore Medical College, Bangalore) as another phlogistic agent; Anesthetic Ether (Industrial Solvents and Chemicals Pvt. Ltd., Bombay) for anesthetising animals; Distilled water (Fluid section of Pharmacy department, VIMS, Bellary) for preparation of solutions and suspensions of various drugs and chemical compounds; Sartorius Analytical Balance with $0.0001 \mathrm{mg}$ sensitivity was used for measuring weights as applicable; Plethysmograph prepared with modifications as per descriptions of Buttle et al, is used in this study. ${ }^{11}$

\section{Animals and investigational products}

\section{Animals}

Wister rats (180-230g) of either sex were used. Sex distribution was equal in each group (total five groups (n $=6$ in each) in each experiment protocol). Animals were acclimatized by housing 7 days prior to experimentation in the laboratory with $22 \pm 2^{\circ} \mathrm{C}$ temperature and $12 \mathrm{hr}$ light/dark cycle. Food and water were available ad libitum. They fasted overnight before conducting acute inflammation experiment. They had free access to water throughout the experiment. Ethical clearance (Ref No. VIMS/PHARMA/33/00-01) was obtained before performing the experiments.

\section{Investigational products}

A $5 \mathrm{ml}$ of water was administered to all animals before feeding investigational products in order to maintain equal hydration. Control group received $4 \%$ plain gum acacia suspension, standard control groups received Diclofenac sodium $(30 \mathrm{mg} / \mathrm{kg})$, nimesulide $(50 \mathrm{mg} / \mathrm{kg})$ as suspension prepared with $4 \%$ gum acacia. Test groups received Thia$1(50 \mathrm{mg} / \mathrm{kg})$ and thia-2 $(50 \mathrm{mg} / \mathrm{kg})$ as suspension prepared with $4 \%$ gum acacia.

\section{Anti-inflammatory models}

\section{Carrageenin-induced paw edema ${ }^{12}$}

Paw edema was induced by injecting $0.1 \mathrm{ml}$ of $1 \%$ carrageenan into the sub plantar region of the left hind paw. All investigational products were given orally to respective groups $1 \mathrm{hr}$ before the injection of carrageenin. Paw volume was determined before injection (basal volume), at carrageenan injection and 1, 2, 3, 4 and $18 \mathrm{hr}$ after injection using the plethysmograph. 


\section{Formalin induced acute peritonitis ${ }^{13}$}

One hr before injection of $1 \mathrm{ml}$ of $2 \%$ Formalin into peritoneal cavity in the iliac region, investigational products were fed to the experimental animals. Four hr later, animals were sacrificed under ether anaesthesia and cervical dislocation and the ascetic fluid was collected by opening abdomen by midline incision. The volume of ascetic fluid collected was measured for all the groups $(\mathrm{N}$ $=6$ for each group).

\section{Formation of granulomatous tissue ${ }^{14}$}

Lower back of rats was cleaned using $70 \%$ spirit and shaved before making $1 \mathrm{~cm}$ incision under ether anaesthesia on both sides for implanting cotton pellet weighing $10 \pm 1 \mathrm{mg}$ each. Daily dose of investigational products was given from the day of implantation and was continued for 7 days. The animals were anesthetized and sacrificed on 8th day by cervical dislocation. The cotton pellets with granulomatous tissue was removed and dried at $70^{\circ} \mathrm{C}$ for $24 \mathrm{hr}$ after measuring wet weight. Wet and dry granuloma weight was defined as the difference between the weight of the tissue and the weight of the initial implanted cotton pellet. $(n=12$ ( 6 rats in each group and two cotton pellets in each rat).

\section{Gastric ulcerogenic activity ${ }^{15}$}

The ulcerogenic activity was expressed on day 8 after rats were euthanized by cervical dislocation, granulomatous tissue with cotton pellets were removed. The stomachs of these rats were removed and placed in $2 \%$ formalin. Each stomach was opened by cutting along the greater curvature and rinsed with $5 \mathrm{ml}$ saline before the macroscopic scoring. Macroscopic scoring by naked eye examination was done as follows: $0=$ normal coloured stomach, $0.5=$ red colouration, $1=$ haemorrhagic streaks, $2=$ ulcers $>3 \mathrm{~mm}$ but $\leq 5 \mathrm{~mm}$, and $3=>5 \mathrm{~mm}$ ulcers. ${ }^{16}$ After macroscopic scoring, tissues were fixed with $10 \%$ formalin buffered solution.
H\&E slides were prepared using representative areas of stomach. Microscopic scoring of gastric lesions was done as follows: $0=$ normal histological appearance, $1=$ inflammatory infiltrate in lamina propria with mucosal surface epithelium, $2=$ necrosis of mucosal surface epithelium, $3=$ necrosis of mucosal glands but limited to superficial half and $4=$ necrosis of mucosal glands extended up to deeper half of mucosal coat. ${ }^{17}$ The pathologist who did ulcer scoring was blinded to treatments received by animals.

\section{Statistical analysis}

Statistical analysis was done using GraphPad InStat ${ }^{\circledR}$ v3.06 software. Results were presented as mean \pm SD for each experimental group. Gastric ulcerogenicity results were analysed using Kruscal-Wallis (Nonparametric ANOVA) test followed by Dunn's multiple comparisons test. Other results were analysed using one way ANOVA followed by the Dunnett multiple comparisons test. Statistical significance was set at $\mathrm{P}<0.05$. Test and standard control groups were compared with control group.

\section{RESULTS}

\section{Anti-inflammatory activity}

\section{Carrageenan paw edema model}

Visible and measurable paw edema was produced by Carrageenan injection. The maximum inflammation was observed at $4 \mathrm{hrs}$ after the carrageenan injection. The groups pre-treated with diclofenac, nimesulide, thia-2 as per dose mentioned in Table 1 exhibited significantly ( $\mathrm{P}$ $<0.01$ ) lower edema formation throughout (from 1 to 18 hrs) the experiment. Thia-1 did not show significant inhibition ( $\mathrm{p}>0.05)$ of edema from 1-4hr after carrageenan injection. But at $18 \mathrm{hr}$ it produced significant inhibition $(\mathrm{p}<0.05)$ (Table 1).

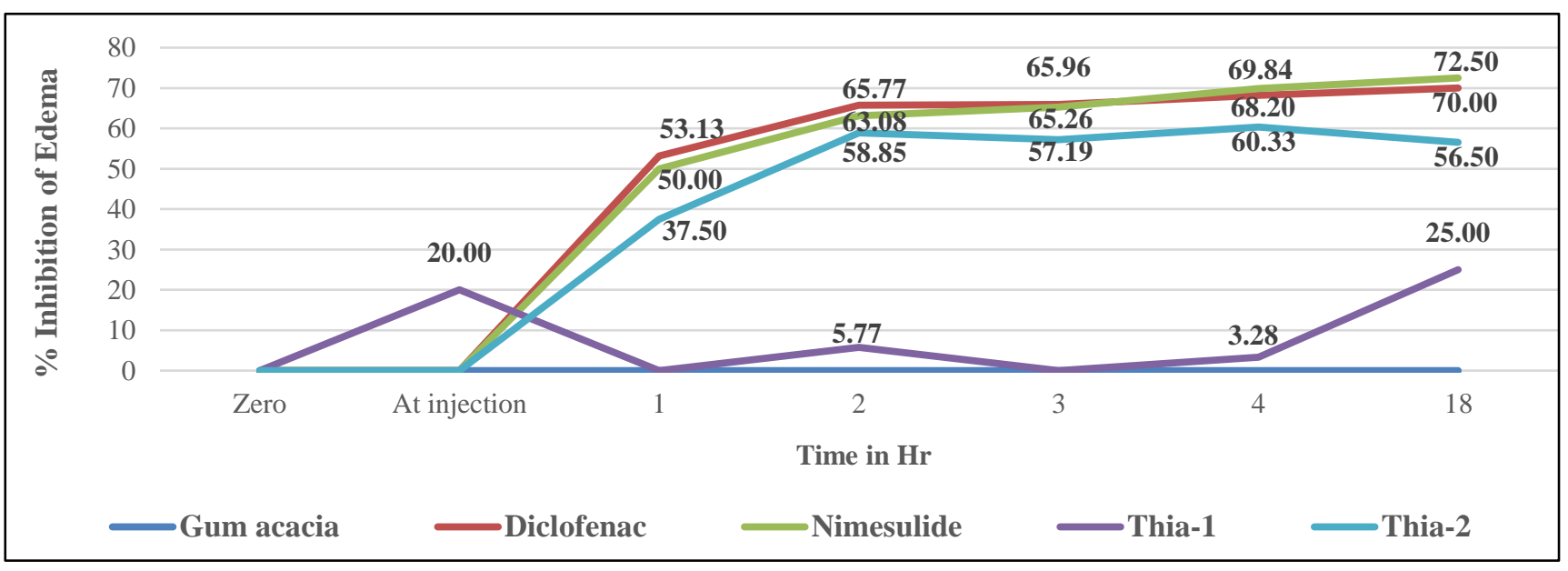

Figure 1: Comparison of percentage inhibition of carrageenan induced paw edema vs time. 
Figure 1 shows the time-course of carrageenan induced rat paw edema and its percentage inhibition by test and standard drugs. Diclofenac and nimesulide exhibited $53.13 \%$ and $50.00 \%$ inhibition respectively at $1 \mathrm{hr}$ Carrageenan injection and reached maximum inhibition by
$18 \mathrm{hr}$ to $70.00 \%$ and $72.50 \%$ respectively. Thia- 2 inhibited $37.50 \%$ of edema at $1 \mathrm{hr}$ and reached maximum inhibition to $60.33 \%$ by $4 \mathrm{hr}$. Thia-1 did not show significant inhibition throughout experiment except at $18 \mathrm{hr}$ time point. It inhibited $25.00 \%$ of edema at $18 \mathrm{hr}$ time point.

Table 1: Effect of diclofenac, nimesulide and thiazolidine-4-one derivatives (Thia-1 and 2), in carrageenan-induced paw edema model in rats.

\begin{tabular}{|c|c|c|c|c|c|c|c|c|}
\hline \multirow{2}{*}{$\begin{array}{l}\text { Treatment } \\
\text { group }\end{array}$} & \multirow[b]{2}{*}{ Dose } & \multicolumn{7}{|c|}{ Edema volume in ml (Mean \pm SD) ( $n=6$ in each group) } \\
\hline & & $\begin{array}{l}\text { Before } \\
\text { injection }\end{array}$ & $\begin{array}{l}\text { At } \\
\text { injection }\end{array}$ & $1 \mathrm{hr}$ & $2 \mathrm{hr}$ & $3 \mathrm{hr}$ & $4 \mathrm{hr}$ & $18 \mathrm{hr}$ \\
\hline Gum acacia & Control & $0.40 \pm 0.03$ & $0.44 \pm 0.04$ & $0.67 \pm 0.03$ & $0.83 \pm 0.04$ & $0.88 \pm 0.03$ & $0.91 \pm 0.04$ & $0.73 \pm 0.05$ \\
\hline Diclofenac & $30 \mathrm{mg} / \mathrm{kg}$ & $0.41 \pm 0.02$ & $0.45 \pm 0.00$ & $0.53 \pm 0.03^{@}$ & $0.56 \pm 0.03^{@}$ & $0.57 \pm 0.02^{@}$ & $0.57 \pm 0.02^{@}$ & $0.51 \pm 0.02^{@}$ \\
\hline Nimesulide & $50 \mathrm{mg} / \mathrm{kg}$ & $0.42 \pm 0.03$ & $0.46 \pm 0.02$ & $0.55 \pm 0.04^{@}$ & $0.58 \pm 0.03^{@}$ & $0.58 \pm 0.03^{@}$ & $0.57 \pm 0.02^{@}$ & $0.51 \pm 0.02^{@}$ \\
\hline Thia-1 & $50 \mathrm{mg} / \mathrm{kg}$ & $0.42 \pm 0.03$ & $0.45 \pm 0.03$ & $0.68 \pm 0.03$ & $0.83 \pm 0.05$ & $0.89 \pm 0.04$ & $0.91 \pm 0.04$ & $0.67 \pm 0.05^{*}$ \\
\hline Thia-2 & $50 \mathrm{mg} / \mathrm{kg}$ & $0.39 \pm 0.04$ & $0.43 \pm 0.03$ & $0.56 \pm 0.08^{@}$ & $0.57 \pm 0.03^{@}$ & $0.60 \pm 0.03^{@}$ & $0.59 \pm 0.04^{@}$ & $0.54 \pm 0.02^{@}$ \\
\hline \multirow{3}{*}{$\begin{array}{l}\text { One way } \\
\text { ANOVA }\end{array}$} & $\mathrm{F}$ & 0.8500 & 0.7738 & 14.4400 & 89.2520 & 171.6600 & 181.9400 & 48.1700 \\
\hline & d.f. & 29 & 29 & 29 & 29 & 29 & 29 & 29 \\
\hline & $\mathrm{P}$ & 0.5071 & 0.5526 & $<0.0001$ & $<0.0001$ & $<0.0001$ & $<0.0001$ & $<0.0001$ \\
\hline
\end{tabular}

* $\mathrm{p}<0.05, @ \mathrm{p}<0.01, \# \mathrm{p}<0.001$ when compared to control group. Intergroup comparison was done using Dunnett multiple comparisons test.

Table 2: Effect of diclofenac, nimesulide and thiazolidine-4-one derivatives (Thia-1 and 2), in formalin induced peritonitis model in rats.

\begin{tabular}{|llll|}
\hline Treatment group & Dose & $\begin{array}{l}\text { Peritoneal exudates volume in } \mathbf{m l} \text { (n=6 in each group) } \\
\text { Mean } \pm \text { SD }\end{array}$ & $\begin{array}{l}\text { Percent } \\
\text { inhibition }\end{array}$ \\
\hline Gum acacia & Control & $7.65 \pm 0.48$ & - \\
\hline Diclofenac & $30 \mathrm{mg} / \mathrm{kg}$ & $4.30 \pm 0.36^{@}$ & $43.79 \%$ \\
\hline Nimesulide & $50 \mathrm{mg} / \mathrm{kg}$ & $4.22 \pm 0.44^{@}$ & $44.88 \%$ \\
\hline Thia-1 & $50 \mathrm{mg} / \mathrm{kg}$ & $7.88 \pm 0.24$ & $-3.05 \%$ \\
\hline Thia-2 & $50 \mathrm{mg} / \mathrm{kg}$ & $4.70 \pm 0.42^{@}$ & $38.56 \%$ \\
\hline \multirow{3}{*}{ One way ANOVA } & $\mathrm{F}$ & 130.8300 & \\
& d.f. & 29 & \\
\hline
\end{tabular}

${ }^{*} \mathrm{p}<0.05,{ }^{\circledR} \mathrm{p}<0.01,{ }^{*} \mathrm{p}<0.001$ when compared to control group. Intergroup comparison was done using Dunnett multiple comparisons test.

\section{Formalin induced peritonitis model}

Rats treated with gum acacia (control group) and thia-1 produced maximal exudation with $7.88 \pm 0.24 \mathrm{ml}$ and $7.65 \pm 0.48 \mathrm{ml}$ respectively. This indicated maximal peritoneal inflammation in these two groups. Diclofenac, nimesulide, and thia- 2 treated animals showed reduced exudation with $4.30 \pm 0.36 \mathrm{ml}, \quad 4.22 \pm 0.44 \mathrm{ml}$ and $4.70 \pm 0.42 \mathrm{ml}$ respectively. All the three drugs reduced peritoneal inflammation significantly $(\mathrm{p}<0.01)$.

Diclofenac reduced exudation by $43.79 \%$, nimesulide by $44.88 \%$, thia- 2 by $38.56 \%$ respectively (Table 2 ). Thia 1 did not show anti-inflammatory effect in this model ( $p$ $>0.05)$.

\section{Cotton pellet granuloma model}

Diclofenac (45.22\%, p<0.01), nimesulide (39.13\%, p $<0.01)$ and thia-2 $(33.96 \%, \mathrm{p}<0.01)$ reduced wet weight of cotton pellets significantly. Thia $1(14.80 \%, \mathrm{p}>0.05) \mathrm{did}$ not reduce it significantly (Table 3 ). In addition, dry weight reduced by diclofenac $(34.99 \%, \mathrm{p}<0.01)$ and thia-2 $(22.51 \%, \mathrm{p}<0.05)$ was significant. Nimesulide $(19.14 \%, \mathrm{p}$ $>0.05)$ and thia- $1(2.68 \%, \mathrm{p}>0.05)$ did not reduce it significantly (Table 3 ).

\section{Gastric ulcerogenic activity}

Both on macroscopic and microscopic examination, nimesulide, thia-1 and thia- 2 did not increase gastric ulcer score significantly $(\mathrm{p}>0.05)$. In contrast, diclofenac 
increased ulcer score both macroscopic (by $77.78 \%$, $\mathrm{p}<0.001$ ) and microscopic (by $70.83 \%, \mathrm{p}<0.001$ ) significantly (Table 4).

\section{DISCUSSION}

Inflammation is characterized by pain, redness, immobility (loss of function), swelling and heat. These may be seen within a few minutes or hours after injurious stimulus which may cease after removal of it. An uncontrolled and persistent inflammation may cause chronic illnesses. ${ }^{18}$

NSAIDs are used to control and treat inflammation. They are heterogeneous class of drugs like aspirin, indomethacin, diclofenac, nimesulide, celecoxib etc., which act by inhibiting $\mathrm{COX}(\mathrm{COX}-1$ and $\mathrm{COX}-2$ nonselectively or COX-2 selectively) enzyme. ${ }^{6,18,19} \mathrm{COX}$ is the rate-limiting enzyme responsible for the production of PGs, prostacyclins and thromboxanes. Inflammatory chemicals like endotoxin, mitogens and cytokines, especially IL-1 induce COX-2 biosynthesis and is responsible for production of enhanced PGs in inflamed tissues. $^{6,15,20,21}$ The beneficial actions of NSAIDs are linked to inhibition of inducible $\mathrm{COX}-2$, and adverse reactions (e.g., gastrointestinal damage) to inhibition of COX-1. NSAIDs are divided into non-selective NSAIDs (inhibit both COX-1 and COX-2 forms) and COXibs (inhibit COX2 selectively). ${ }^{6}$ More than 144 NSAIDs are available for clinical use worldwide. Still search continues for a better and safer one. ${ }^{22}$

Table 3: Effect of diclofenac, nimesulide and thiazolidine-4-one derivatives (Thia-1 and 2), in cotton pellet granuloma model in rats.

\begin{tabular}{|c|c|c|c|c|c|}
\hline \multirow{2}{*}{$\begin{array}{l}\text { Treatment } \\
\text { group }\end{array}$} & \multirow{2}{*}{ Dose } & \multicolumn{2}{|c|}{$\begin{array}{l}\text { Wet weight of cotton pellets in } \mathrm{mg} \text { (after } \\
\text { deducting initial weight) } \\
\text { ( } \mathrm{n}=12 \text { in each group) }\end{array}$} & \multicolumn{2}{|c|}{$\begin{array}{l}\text { Dry weight of cotton pellets in } \mathrm{mg} \\
\text { (after deducting initial weight) } \\
\text { ( } \mathrm{n}=12 \text { in each group) }\end{array}$} \\
\hline & & Mean \pm SD & $\begin{array}{l}\text { Percentage inhibition } \\
\text { of granuloma } \\
\text { formation }\end{array}$ & Mean \pm SD & $\begin{array}{l}\text { Percentage inhibition } \\
\text { of granuloma } \\
\text { formation }\end{array}$ \\
\hline Gum acacia & Control & $379.34 \pm 128.10$ & - & $71.81 \pm 16.27$ & - \\
\hline Diclofenac & $30 \mathrm{mg} / \mathrm{kg}$ & $207.79 \pm 48.19^{@}$ & $45.22 \%$ & $46.68 \pm 6.82^{@}$ & $34.99 \%$ \\
\hline Nimesulide & $50 \mathrm{mg} / \mathrm{kg}$ & $230.92 \pm 62.68^{@}$ & $39.13 \%$ & $58.07 \pm 15.79$ & $19.14 \%$ \\
\hline Thia-1 & $50 \mathrm{mg} / \mathrm{kg}$ & $323.22 \pm 52.98$ & $14.80 \%$ & $69.88 \pm 21.74$ & $2.68 \%$ \\
\hline Thia-2 & $50 \mathrm{mg} / \mathrm{kg}$ & $250.52 \pm 52.09^{@}$ & $33.96 \%$ & $55.64 \pm 12.40 *$ & $22.51 \%$ \\
\hline \multirow{3}{*}{$\begin{array}{l}\text { One way } \\
\text { ANOVA }\end{array}$} & $\mathrm{F}$ & 10.7600 & & 5.5150 & \\
\hline & d.f. & 59 & & 59 & \\
\hline & $\mathrm{P}$ & $<0.0001$ & & 0.0008 & \\
\hline
\end{tabular}

${ }^{*} \mathrm{p}<0.05,{ }^{\circledR} \mathrm{p}<0.01,{ }^{\#} \mathrm{p}<0.001$ when compared to control group. Intergroup comparison was done using Dunnett multiple comparisons test.

Table 4: Effect of diclofenac, nimesulide and thiazolidine-4-one derivatives (Thia-1 and 2), on gastric ulcer index in rats.

\begin{tabular}{|c|c|c|c|c|c|}
\hline \multirow{2}{*}{ Treatment group } & \multirow{2}{*}{ Dose } & \multicolumn{2}{|c|}{$\begin{array}{l}\text { Macroscopic scoring } \\
\text { (Kulkarni's method) }\end{array}$} & \multicolumn{2}{|c|}{$\begin{array}{l}\text { Microscopic scoring } \\
\text { (Lacy and Ho's method) }\end{array}$} \\
\hline & & Mean \pm SD & $\begin{array}{l}\text { Percentage } \\
\text { increase in ulcer }\end{array}$ & Mean \pm SD & $\begin{array}{l}\text { Percentage } \\
\text { increase in ulcer }\end{array}$ \\
\hline Gum acacia & Control & $0.17 \pm 0.26$ & $5.56 \%$ & $0.33 \pm 0.52$ & $8.33 \%$ \\
\hline Diclofenac & $30 \mathrm{mg} / \mathrm{kg}$ & $2.33 \pm 0.52^{\#}$ & $77.78 \%$ & $2.83 \pm 1.17^{@}$ & $70.83 \%$ \\
\hline Nimesulide & $50 \mathrm{mg} / \mathrm{kg}$ & $0.42 \pm 0.20$ & $13.89 \%$ & $0.50 \pm 0.84$ & $12.50 \%$ \\
\hline Thia-1 & $50 \mathrm{mg} / \mathrm{kg}$ & $0.42 \pm 0.80$ & $13.89 \%$ & $1.00 \pm 1.26$ & $25.00 \%$ \\
\hline Thia -2 & $50 \mathrm{mg} / \mathrm{kg}$ & $0.42 \pm 0.20$ & $13.89 \%$ & $0.83 \pm 0.41$ & $20.83 \%$ \\
\hline \multirow{3}{*}{$\begin{array}{l}\text { Kruscal-Wallis } \\
\text { (nonparametric } \\
\text { ANOVA) Test }\end{array}$} & KW & 17.3130 & & 13.1340 & \\
\hline & d.f. & 29 & & 29 & \\
\hline & $\mathrm{P}$ & 0.0017 & & 0.0106 & \\
\hline
\end{tabular}

${ }^{*} \mathrm{p}<0.05,{ }^{\circledR} \mathrm{p}<0.01,{ }^{\#} \mathrm{p}<0.001$ when compared to control group. Intergroup comparison was done using Dunn's multiple comparisons test.

Carrageenan induced paw edema model is widely used to investigate the pathophysiology of the inflammatory response and to characterize the novel anti-inflammatory drugs. ${ }^{5,18,23,24}$ Carrageenan injection produces two inflammatory phases and a third, uncharacteristic phase. 
Increased vascular permeability in first hour is implicated to release of histamine and serotonin, in second hour to kinins and in third hour to PGs respectively. ${ }^{25}$ In this study, pre-treatment with diclofenac, nimesulide and thia-2 inhibited paw edema at all time points $(p<0.01)$; however, higher inhibition was observed in $2^{\text {nd }}$ and $3^{\text {rd }}$ hour after induction of inflammation. This observation suggests inhibition of release of histamine, serotonin, kinins and PGs by diclofenac, nimesulide and thia- 2 .

Teotino et al, described about formalin induced peritonitis model. ${ }^{13}$ Formalin injection into peritoneal cavity irritates the peritoneum and bowel resulting in acute inflammatory reactions with aseptic peritonitis due to release of PGs, serotonin and histamine. Due to release of these chemical mediators extravasation of fluid, with chemotaxis due to neutrophil dependent inflammatory pathways is also observed. In addition, neurogenic inflammation mediators like neuropeptides e.g. substance $\mathrm{P}$ is also released. ${ }^{26,27}$ Diclofenac, nimesulide and thia-2, reduced peritoneal exudation significantly $(\mathrm{p}<0.01)$ in this study. This suggests that the ability of these drugs to suppress peritonitis by reducing release of bradykinin, PGs, histamine, serotonin and neutrophils mediated inflammation.

Insufficient acute inflammatory responses failing to eliminate pro-inflammatory agents leads to chronic inflammation changes. These include, infiltration of neutrophils with transudation, exudation of fluid, proliferation of macrophages, neutrophils and fibroblasts, spreading of fibroblasts and formation of granuloma. Cotton pellet induced granuloma model is widely used to test the ability of drugs to inhibit these chronic inflammatory responses. Transudate phase causes increase in the wet weight of the cotton pellet while hosting inflammatory responses to the implanted cotton pellet between 3 and 6 days causes granuloma formation. Therefore, increase in dry weight is considered as a measure of proliferative component of inflammation. ${ }^{2,28}$ In this study, diclofenac, nimesulide and thia- 2 reduced wet weight of cotton pellets significantly $(p<0.01)$. In addition, diclofenac $(\mathrm{p}<0.01)$ and thia-2 $(\mathrm{p}<0.05)$ reduced dry weight of cotton pellets significantly. Nimesulide reduced dry weight by $19.14 \%$, which missed statistical significance $(p>0.05)$ marginally. This reduction in both wet and dry weights is correlated with their ability to reduce transudation, synthesis of collagen and mucopolysaccharides, proliferation of fibroblasts and formation of granuloma.

PGs produced by non-inducible COX are having mucoprotective with ulcer healing property by formation of cytoprotective layer and increasing bicarbonate ions secretion. This is known to neutralise the gastric acidity. On the contrary, therapeutically useful NSAIDs act by inhibiting COX enzyme non-selectively. This is leading to disturbances in homeostatic mechanisms and gastric ulceration. Additionally, ulceration due to NSAIDs linked to hypoxia due to vasoconstriction and 'ion trapping' (due to their low $\mathrm{pKa}$ and weak organic acid property). ${ }^{4,6,25,29}$ In the present study, Nimesulide, thia-1 and thia-2 did not increase gastric ulcer score significantly $(p>0.05)$. In contrast, diclofenac increased both macroscopic $(77.78 \%$, $\mathrm{p}<0.001)$ and microscopic $(70.83 \%, \mathrm{p}<0.01)$ ulcer score significantly. This suggests its ability to inhibit COX enzyme non-selectively. In contrast, nimesulide and thia-2 demonstrated anti-inflammatory effect in all the three models but did not show ulcerogenic effect. This indicates their ability to inhibit inducible COX enzyme predominantly.

PPAR receptors agonistic activity of TZDs is well documented. Deficiency of PPAR $\alpha$ receptors in mice was presented with increased inflammatory responses by leukotriene B4 and arachidonic acid. In-vitro and in-vivo studies of PPAR $\alpha$ agonists shown to have antiinflammatory activity through inhibition of expression of COX-2 genes induced by IL-1B and inhibition of production of interleukin IL-6, IL-8, PGs, cytokines resulting in reduction of cell influx, edema and thermal allodynia. ${ }^{8}$ Considering the results of this study, we can conclude that thia-2 exhibited its anti-inflammatory activity in both acute and chronic models. Possible mechanism of action may be attributed to inhibition of release of histamine, serotonin, kinins and PGs in acute inflammation and also inhibition of chronic inflammatory responses like transudation, synthesis of collagen and mucopolysaccharides, proliferation of fibroblasts and formation of granuloma. PPAR receptors agonistic activity may also be proposed as the additional mechanism for its anti-inflammatory responses.

Hawkey CJ, described the structure of COX-2 and difference between COX 1 and COX-2. He highlighted the role of sulphonyl, sulphonamide or sulphone groups in side chain of COX-2 selective inhibitors in binding the side pocket of this enzyme. ${ }^{30}$ Incidentally, it is worth to note the presence of Sulphonyl group in test drugs of this study. Researchers also highlighted the importance of presence of isoleucine and valine (smaller by a methyl group compared to isoleucine) amino acids at 523 position in structure of COX-1 and COX-2 respectively. They stated that the bulkier isoleucine in COX-1 is large enough to block the access to its side pocket. Targeted single amino acid substitution of valine for isoleucine is sufficient to turn COX-1 into an enzyme that can be inhibited by COX-2 selective agents. Flurbiprofen was used to demonstrate this. The progressive modification and extension of Flurbiprofen's methyl group resulted in molecules that were increasingly selective in their ability to bind to the COX-2 side pocket, but too bulky to fit within the COX-1 channel. ${ }^{30}$ Authors of this study agree with these statements related to the modification of methyl group to increase the COX-2 selectivity. Current study demonstrated addition of 2 methyl groups to the side chain of Thia- 1 modified it from low anti-inflammatory agent to potent antiinflammatory agent with possible selective COX-2 inhibition. In addition to this, considering Hawkey's descriptions, we propose a hypothesis for further research 
such as "methylation of conventional NSAIDs may increase their selectivity towards $\mathrm{COX}-2$ as they become bulkier by one or more methyl groups". ${ }^{30}$ If this hypothesis is proved to be true, more number of NSAIDs may be methylated to convert them into bulkier ones sparing COX1 enzyme. This new class may be called as 'Methylated NSAIDs'.

Limitations of this study includes adjuvant arthritis model is considered as the best for screening anti-inflammatory and anti-rheumatic property of newer compounds. This model is sensitive in Lewis rats and it is a 28days procedure. ${ }^{31}$ Due to non-availability of Lewis rats and insufficient amount of test drugs, this model was not used in author's study. In-vitro specific enzyme inhibition, estimation of $\mathrm{pKa}$ and acidity studies were not done. Therefore, the conclusions made are at possible or probable level. Additional studies using different species of rodents and non-rodent models in addition to in-vitro studies are required to confirm the results.

\section{CONCLUSION}

Thia-2 demonstrated significant anti-inflammatory activity in acute and chronic models. In addition to inhibition of cyclooxygenase pathway, PPAR agonistic activity may be involved in its anti-inflammatory activity. No significant ulcerogenicity was observed on comparing with nimesulide and control. Further in-vitro and in-vivo studies are recommended to confirm the results of this study.

\section{ACKNOWLEDGEMENTS}

Authors would like to acknowledge the support and encouragement extended by Dr. Basalingappa, HOD, Pharmacology Department DMWIMS, Wayanad, its management and staff. Authors also thank Mrs. Sowmya Nataraj, Bangalore for proof reading support.

Funding: No funding sources Conflict of interest: None declared

Ethical approval: The study was approved by the Institutional Ethics Committee (Ref No.VIMS/PHARMA/33/00-01)

\section{REFERENCES}

1. Abdulkhaleq LA, Assi MA, Abdullah R, Zamri-Saad M, Taufiq-Yap YH, Hezmee MN. The crucial roles of inflammatory mediators in inflammation: a review. Veterinary World. 2018 May;11(5):627-35.

2. Bagad AS, Joseph JA, Bhaskaran N, Agarwal A. Comparative evaluation of anti-inflammatory activity of curcuminoids, turmerones, and aqueous extract of Curcuma longa. Adv Pharmacol Sci. 2013;2013.

3. Hawkins C, Hanks GW. The gastroduodenal toxicity of nonsteroidal anti-inflammatory drugs: a review of the literature. J Pain Symptom Manage. 2000 Aug;20(2):140-51.
4. Thabrew MI, Arawwawala LDAM. An overview of in-vivo and In-vitro models that can be used for evaluating anti-gastric ulcer potential of medicinal plants. Austin Biol. 2016;1(2):1007

5. Madhuri AS, Mohanvelu R, Ramabhimaiah S. Evaluation of anti-inflammatory activity of aqueous extract of Mangifera indica leaves in albino rats. Int $\mathbf{J}$ Basic Clin Pharmacol. 2016 Dec 30;5(3):635-8.

6. Venerito M, Wex T, Malfertheiner P. Nonsteroidal anti-inflammatory drug-induced gastroduodenal bleeding: risk factors and prevention strategies. Pharmaceuticals. 2010 Jul 14;3(7):2225-37.

7. Faizan S, Abdul S, Akram MD. Analgesic and antiinflammatory activity of new substituted Thiazolidin4-One Derivatives. Indo Am J P Sci. 2017:4(08);246172.

8. de Magalhães LR, Alves IB, dos Santos E, da Silva VB, da Silva LC, da Silva AL, et al. Activity antiinflammatory and in silico study of new thiazolidinedione derivatives. Br J Pharmaceut Res. 2014 Jul 15;4(14):1739.

9. Shiva MN, Srinivasa V. Screening of new synthetic thiazolidine-4-ones for anti-inflammatory activity in albino rats. Indian J Pharmacol. 2003 Jan 1;35(1):61.

10. Sushma M, Sudha S, Shivamurthy N, Venkataraman $\mathrm{BV}$. Analgesic activity of new synthetic thiazolidine4-ones derivatives. Indian $\mathbf{J}$ Experimental Biol 2004;42:812-5.

11. Buttle GA, D'arcy PF, Howard EM, Kellett DN. Plethysmometric measurement of swelling in the feet of small laboratory animals. Nature. 1957 Mar;179(4560):629.

12. Winter CA, Risley EA, Nuss GW. Carrageenininduced edema in hind paw of the rat as an assay for antiinflammatory drugs. Proceedings Soc Exp Biol Med. 1962 Dec;111(3):544-7.

13. Teotino UM, Friz LP, Gandini A, Bella DD. Thio derivatives of 2, 3-dihydro-4H-1, 3-benzoxazin-4-one. Synthesis and pharmacological properties. J Medicin Chem. 1963 May;6(3):248-50.

14. Swingle KF, Shideman FE. Phases of the inflammatory response to subcutaneous implantation of a cotton pellet and their modification by certain antiinflammatory agents. J Pharmacol Experiment Therapeut. 1972 Oct 1;183(1):226-34

15. Ochi T, Goto T. Anti-inflammatory activity of a novel selective cyclooxygenase-2 inhibitor, FR140423, on type II collagen-induced arthritis in Lewis rats. Prostaglandins Other Lipid Mediators. 2001 Dec 1;66(4):317-27.

16. Jain NK, Singh A, Kulkarni SK. Analgesic, antiinflammatory and ulcerogenic activity of a zincnaproxen complex in mice and rats. Pharmacy Pharmacol Communications. 1999 Oct;5(10):599602.

17. De Leval X, Henrotin Y, Labasse A, Reginster JY, Neven P, Delarge J, et al. Comparison of the Effects of Nimesulide and Nimesulide-L-lysine on PGE2 Production by COX-1 and COX-2 and on 
Chondrocyte Metabolism In-vitro. Pharmacy Pharmacol Communications. 2000 Feb;6(2):83-7.

18. Kamble S, Ahmed MZ, Ramabhimaiaha S, Patil P. Anti-inflammatory activity of Raphanus sativus L in acute and chronic experimental models in Albino rats. Biomed Pharmacol J. 2013;6(2):315-20.

19. Sharma V, Laxmi V, Chauhan S. Cyclooxygenase-3: a review. Am J Pharm Tech Res. 2012;2(3):236-42

20. Batlouni M. Nonsteroidal anti-inflammatory drugs: cardiovascular, cerebrovascular and renal effects. Brazilian Arch Cardiol. 2010 Apr; 94 (4): 556-63.

21. Dhikav V, Singh S, Pande S, Chawla A, Anand KS. Non-steroidal drug-induced gastrointestinal toxicity: mechanisms and management. J Indian Acad Clin Med. 2003 Oct;4(4):315-22.

22. Rosenbloom D, Craven MA. A review of nonsteroidal anti-inflammatory drugs. Canad Fam Physician. 1983 Nov;29:2121.

23. Veloso CC, Cabral LD, Bitencourt AD, Franqui LS, Santa-Cecília FV, Dias DF, et al. Anti-inflammatory and antinociceptive effects of the hydroethanolic extract of the flowers of Pyrostegia venusta in mice. Braz J Pharmacognosy. 2012 Feb;22(1):162-8.

24. Verdam MC, Guilhon-Simplicio F, Andrade KC, Fernandes KL, Machado TM, da Silva FM, et al. Analgesic, anti-inflammatory, and antioxidant activities of Byrsonima duckeana WR Anderson (Malpighiaceae). Scientific World J. 2017;2017.

25. Borges JC, de Sousa Aguiar RW, de Sousa JE, Ripardo Filho HS, Guilhom GS, Santos LS, et al. Antiinflammatory and non ulcerogenic activities of acetylbergenin. Afr J Pharmacy Pharmacol. 2017 Sep 8;11(33):402-10.

26. Bhuvana KB, Hema NG. An evaluation of Aloe Vera for its acute anti-inflammatory activity in rat peritonitis model. World $\mathrm{J}$ Pharmaceut Res. 2014;3(3):4508-19

27. Rosa MD, Willoughby DA. Screens for antiinflammatory drugs. J Pharmacy Pharmacol. 1971 Apr;23(4):297-8.

28. Ramakrishnan G, Joshua AJ, Goudar K, Amit A. Comparative evaluation of anti-inflammatory activity of different extracts of Boswellia serrata in Wistar Albino rats. Int J of PharmTech Res. 2011;3(1):261-7

29. Sharma GN, Dubey SK, Sati N, Sanadya J. Ulcer healing potential of Aegle marmelos fruit seed. Asian J Pharm Life Sci. 2011 Mar;1(2):172-8.

30. Hawkey CJ. COX-2 inhibitors. Lancet. 1999 Jan 23;353(9149):307-14.

31. Walz DT, DiMartino MJ, Misher A. Adjuvant-induced arthritis in rats. II. Drug effects on physiologic, biochemical and immunologic parameters. J Pharmacol Exp Therapeut. 1971 Jul 1;178(1):223-31.

Cite this article as: Murthy SN, Srinivas V, Shanthi M. Anti-inflammatory and ulcerogenic activities of thiazolidine-4-ones in rats. Int $\mathrm{J}$ Basic Clin Pharmacol 2019;8:8-15. 